\title{
MAQUIAVEL: A FORÇA, O PODER E A RETÓRICA
}

\author{
MACHIAVELLI: FORCE, POWER AND RHETORIC
}

Helton Adverse*

\section{RESUMO}

O presente artigo visa examinar as relações entre poder, força e retórica no pensamento de Maquiavel. A obra do secretário florentino nos liberta da ilusão segundo a qual o poder é idêntico à força, nos mostrando que seu exercício é impossível sem a dimensão discursiva. Apenas levando esse fato em consideração, podemos apreender a realidade política em sua complexidade.

PALAVRAS-CHAVES: Poder. Retórica. Força. Discurso. Maquiavel.

\section{ABSTRACT}

This article aims to examine the relations between power, force and rhetoric in Machiavelli 's thinking. The work of the Florentine secretary frees us from the illusion that power is identical with force, showing us that its exercise is impossible without the discursive dimension. Only by taking this fact into account can we grasp the political reality in its complexity.

KEY WORDS: Power. Rhetoric. Force. Speech. Machiavelli.

Podemos abordar o tema da relação entre poder e retórica em Maquiavel a partir de duas perspectivas distintas, porém complementares. A primeira delas coloca em foco o uso que Maquiavel faz da arte retórica, na esteira dos humanistas do Renascimento que haviam realizado o admirável trabalho de reconstituir a tradição retórica grega e romana. Nesse caso, trata-se de chamar a atenção para a presença, nos textos de Maquiavel, das figuras de linguagem, para a modulação de seu discurso, para a variedade de seu estilo e para as estratégias argumentativas que ele mobiliza tendo em vista a persuasão de seu leitor. A segunda perspectiva enfatiza a natureza retórica do exercício do poder político, isto é, trata-se de enfatizar a relação forte entre a ação e o discurso. Tendo em vista nossos propósitos, isto é, discutir a questão do poder e da retórica, devemos privilegiar a segunda abordagem, levando em conta o fato de que ela conduz diretamente a temas cruciais não apenas no pensamento maquiaveliano, mas na história do pensamento político.

Um desses temas concerne àquilo que especifica o poder político. Via de regra, destaca-se sua natureza coercitiva, o fato de ele estar a serviço de uma forma de dominação que não dispensa o uso da força ou da violência. Ora, se esta é, indiscutivelmente, uma das

\footnotetext{
* Doutor em Filosofia. Pós-doutor na Ecole des Hautes Études en Sciences Sociales, EHESS, França. Professor do PPG do Departamento de Filosofia da UFMG. E-mail: heltonadverse @ hotmail.com.
} 
dimensões da vida política, nada nos obriga a acreditar que ela seja seu núcleo ou mesmo seu aspecto essencial. Há boas razões para acreditarmos, assim como o fizeram um número expressivo de filósofos, que a violência revela uma face do poder sem, no entanto, coincidir com ele ${ }^{1}$. Em Maquiavel, apontar essa diferença é tão mais importante quanto o florentino é, comumente, identificado como um defensor do uso da força na política, como um precursor da Machtpolitik ${ }^{2}$. Ora, o que queremos demonstrar nesta breve exposição é que se Maquiavel concede em sua reflexão política um lugar privilegiado à retórica é justamente porque reconhece que o campo da ação política não pode ser reduzido à força nem à violência ${ }^{3}$. Nesse sentido, Maquiavel não apenas aceita, mas trabalha com a oposição clássica entre persuasão e força. É preciso ressaltar, contudo, que essa oposição não implica a radical exclusão ente as duas formas de ação política. Na verdade, suas relações são complexas, uma vez que a persuasão, por si só, não é politicamente efetiva de modo contínuo e duradouro; por outro lado, a força, por ela mesma, é ineficaz para assegurar a eficácia da ação política. Dizendo de outro modo, a retórica é necessária no campo da política porque toda ação está inserida em uma "rede simbólica", ou uma "rede de significados", como diria Claude Lefort (1972, p. 322) na qual o discurso e a força remetem um ao outro. Vamos tentar destrinchar essa relação cerrada entre retórica e força partindo de três passagens dos textos de Maquiavel.

\section{A ASTÚCIA DA RAPOSA}

A primeira passagem encontramos no capítulo XVIII de $O$ príncipe. Em um texto muito conhecido, Maquiavel afirma que há duas formas de "combater": a primeira com as leis e a outra com a força. Ainda segundo ele, a primeira forma "é própria do homem", enquanto a segunda é típica das "bestas” (MACHIAVELLI, 1993, p. 283). A ação política consistiria, então, em um misto de humanidade e animalidade e, para descrever essa dupla natureza,

\footnotetext{
${ }^{1}$ Hannah Arendt é, sem dúvida, uma das autoras que insistiu com mais veemência na distinção entre poder e violência.

${ }^{2}$ A esse respeito, é uma leitura muito proveitosa os capítulos 2 e 3 de Lefort (1972), assim como o livro de Diogo Pires Aurélio (2012), especialmente os capítulos 2, 3 e 4.

${ }^{3}$ Como afirma Newton Bignotto, para Maquiavel "a força não oferece, portanto, um ponto de vista a partir do qual todos os juízos políticos podem ser emitidos. Ela é parte essencial, mas seu uso, longe de reduzir o cenário político a alguns poucos elementos, o transforma, modificando as condições iniciais da ação" (BIGNOTTO, 2015, p. 100).
} 
Maquiavel irá se servir da imagem do centauro ${ }^{4}$, o qual era apontado pelos pensadores antigos como o preceptor dos príncipes por excelência. (MACHIAVELLI, 1993, p. 283). À primeira vista, poderíamos identificar o modo de proceder pelas "leis" com o discurso, ao passo que a força seria o atributo próprio da animalidade. No entanto, Maquiavel embaralha essa distribuição, mostrando que do lado da besta encontramos também algo que pode ser reconhecido como humano. Com efeito, "usar da besta" não consiste somente em servir-se da força, mas também da astúcia. E é precisamente no que concerne à astúcia que desponta a dimensão retórica da ação política ${ }^{5}$. Vejamos como Maquiavel coloca o problema:

\begin{abstract}
Sendo, então, necessário a um príncipe saber bem usar a besta, deve desta tomar a raposa e o leão, porque o leão não se defende das armadilhas, a raposa não se defende dos lobos. Necessita, então, ser raposa para conhecer as armadilhas e leão para assustar os lobos. Aqueles que simplesmente agem como o leão não entendem do assunto. Não pode, portanto, um senhor prudente, nem deve, observar a palavra dada (fede), quando tal observância lhe seja desvantajosa e quando desapareceram as razões que o fizeram prometer. $\mathrm{E}$ se os homens fossem todos bons esse preceito não seria bom. Mas porque são maus, e não a observam para com você, você também não deve observá-la para com eles, nem faltarão jamais a um príncipe motivos legítimos para mascarar a inobservância. Sobre isso, poder-se-iam dar infinitos exemplos modernos e mostrar quantas pazes, quantas promessas ficaram írritas e vãs pela falta de palavra dos príncipes: e aquele que melhor soube usar a raposa foi quem melhor se saiu. Mas esta natureza é preciso sabê-la mascarar bem e ser grande simulador e dissimulador: e são tão simples os homens, e obedecem tanto às necessidades presentes, que aquele que engana encontrará sempre que se deixará enganar. (MACHIAVELLI, 1993, p. 283; MAQUIAVEL, 2008, p. 146).
\end{abstract}

Como podemos ver, a astúcia da raposa é caracterizada aqui por duas qualidades: a primeira é uma forma de conhecimento. "Conhecer as armadilhas", diz Maquiavel, o que assinala claramente sua natureza prudencial visto estar alicerçada na experiência e se configurar como uma capacidade de previsão. Por outro lado, a astúcia da raposa é também capacidade de simulação e dissimulação, o que significa sua inscrição no domínio da imagem e da aparência. Não há dúvida de que é esta última qualidade que mais a aproxima da retórica. Em que sentido?

Simular e dissimular correspondem a duas relações com a aparência ${ }^{6}$. Na primeira, trata-se de "fazer ver algo que não está presente", ao passo que na segunda trata-se de “impedir que algo presente seja visto". Em ambos os casos, o exercício do poder está

\footnotetext{
${ }^{4}$ Para o conhecimento da rica e variada tradição interpretativa da imagem do centauro em Maquiavel, remetemos o leitor ao livro de Thierry Ménissier, Machiavel ou la politique du centaure (2010). Ver também Adverse (2009).

${ }^{5} \mathrm{O}$ "corte", portanto, entre "humano" e "besta" não coincide com a distinção discurso e força, mas com a separação entre "ação ordinária" e "ação extraordinária".

${ }^{6}$ A respeito, ver especialmente Adverse (2009, capítulo 1 e 2), mas também Ames (2015, p. 109-26).
} 
indexado pela imagem, construída sobretudo pelo discurso do príncipe, entendendo por "discurso" tanto aquilo que o príncipe enuncia quanto a estrutura narrativa que se depreende de suas ações. Mais uma vez, é necessário voltar ao texto de Maquiavel: “A um príncipe não é, pois, necessário ter de fato todas as supracitadas qualidades, mas é bem necessário parecer tê-las." (MACHAIVELLI, 1993, p. 284; MAQUIAVEL, 2008, p. 197). As "supracitadas qualidades" são justamente aquelas que compõem a imagem do príncipe como homem piedoso, íntegro, confiável, religioso e humano. Maquiavel quer nos convencer de que elas são danosas para o governante que as possui "realmente" na medida em que podem se transformar em impedimentos para a ação, limitando sua eficiência. Por isso o príncipe deve saber "entrar no mal" quando preciso for, o que requer que ele mantenha com relação a essas qualidades uma distância, uma liberdade que assegure sua transgressão no momento oportuno. Mas o que interessa ressaltar é que essa transgressão não pode ferir a imagem tradicional do bom governante porque sem ela o exercício do poder esbarra no enorme obstáculo do desprezo, da aversão e do ódio. Por esse motivo, Maquiavel não hesita em recomendar que todo governante deve estar atento para que de sua boca "jamais saia algo que não esteja repleto das cinco qualidades e "que pareça, quando é visto e ouvido, inteiramente piedade, fé, integridade, humanidade e religião" (MACHIAVELLI, 1993, p. 284; MAQUIAVEL, 2008, p. 197).

Passando ao largo do problema crucial para Maquiavel - o da necessidade de entrar no mal - o que nos interessa destacar é o fato de que a política é entendida como o campo da aparência. E isso nos permite estreitar o laço entre poder e retórica segundo duas vias.

1) $\mathrm{Na}$ primeira, percebemos que a política mantém com a retórica um parentesco evidente, poderíamos dizer uma consanguinidade. Se o poder não pode dispensar a aparência é porque o espaço em que ele é exercido é o da opinião. Para retomarmos a expressão grega, a esfera pública é o lugar da doxa, o que significa que o discurso que aí circula não pode ter a mesma consistência argumentativa do discurso que se pretenda demonstrativo, como de resto já havia sugerido Aristóteles. De natureza persuasiva, o discurso retórico está no campo da probabilidade e da verossimilhança, isto é, daquilo que pode ser reconhecido como verdadeiro, mas que não pode alcançar a estabilidade da demonstração ${ }^{7}$. Consequentemente, o discurso retórico é afetado por uma instabilidade constitutiva ${ }^{8}$, que é também uma abertura

\footnotetext{
${ }^{7}$ Ver o começo do livro da Retórica, mais precisamente de 1354a até 1358a (ARISTOTE, 1991, p. 16-30).

${ }^{8}$ Instabilidade que Paul Ricœur denomina de "fragilidade" (RICOEUR, 1991, p. 161-2) justamente para marcar o contraste com a "solidez" da demonstração. Não estamos certos se a denominação é apropriada, mas ela
} 
para a realidade e a possibilidade de sua transformação. Esse discurso é construído a partir dessa realidade e visa a responder a suas exigências. A retórica, portanto, está desprovida da solenidade da verdade, colhendo no solo em que as opiniões entram em conflito o húmus que a alimenta. Podemos nos dar conta, então, de que o poder e o discurso têm a mesma origem, ambos estão enraizados no terreno da doxa.

2) Na segunda via, poder e retórica, enraizados na doxa, desvelam sua natureza persuasiva. Eles visam, portanto, um público e dependem, em larga medida, do assentimento desse público para que de fato possam se configurar como forma de ação no espaço político. Maquiavel faz clara alusão a esse fato quando lembra que o que tem realmente peso no exercício do poder é o "juízo do vulgo", isto é, a "opinião dos muitos” (MACHIAVELLI, 1993, p. 284; MAQUIAVEL, 2008, p. 198). Que essa opinião se atenha à superfície, que os muitos "julguem com os olhos", em nada a desqualifica; pelo contrário. Menos do que denunciar a incapacidade política dos muitos, importa a Maquiavel liberar seu leitor (sobretudo aqueles que de fato exercem o poder) da ilusão perigosa de que o príncipe tem pleno domínio sobre a opinião, ao mesmo tempo em que esclarece que ele não pode governar sem ela. Isso significa que se lermos o texto de Maquiavel como um libelo em favor da manipulação do povo vamos deixar escapar sua verdade mais profunda, aquela que nos diz que o príncipe apenas pode existir nesse lugar externo a ele mesmo em que se cristaliza (mas nunca definitivamente) a opinião pública ${ }^{10}$. Nesse sentido, o poder sempre é exercido sob condição, e é isso que torna imprescindível o cuidado com a aparência (ou com a aparição). É também o que permite entender a natureza retórica do próprio poder, sua pertença a um regime de visibilidade estruturado discursivamente.

Voltemos, então, à imagem da raposa astuta. Sua arte de simular e dissimular, de entrar no jogo da aparência sem ser vítima das armadilhas, é conditio sine qua non para o exercício do poder. Mas essa previdência, essa espécie de métis, é também a consciência dos limites. O olhar da raposa não é capaz de perscrutar integralmente o terreno em que se move. E, na verdade, ela é tão mais astuta quanto mais está ciente de que nem tudo é visível, em duplo sentido: nem tudo é visível para alguém em particular (sua visão é sempre uma perspectiva) e nem tudo é visível em geral, isto é, nem tudo está sujeito ao regime de

\footnotetext{
interessa na medida em que coloca a nu a suscetibilidade à mudança e a permeabilidade aos acontecimentos típicas do discurso retórico.

9 Enquanto os "poucos julgam com as mãos" (MACHIAVELLI, 1993, p. 284; MAQUIAVEL, 2008, p. 197).

${ }^{10}$ Para Maquiavel, diz Claude Lefort, “o príncipe existe somente para os outros"; ou ainda, "seu ser está do lado de fora" (LEFORT, 1972, p. 408).
} 
visibilidade. Assim como na pintura, há um ponto de fuga para a política. Ele é pressuposto, mas não pode ser trazido para o interior do quadro. E, sem ele, as linhas que organizam a visão não poderiam se arranjar. O poder, para Maquiavel, tem um outro; um outro que não lhe é absolutamente estranho; que é mesmo um de seus aspectos; que não é propriamente discursivo e que mantém, no entanto, relação com o discurso e a visibilidade. Trata-se, não é difícil adivinhar, do leão, isto é, da força.

\section{UM PROFETA DESARMADO}

A passagem que vamos utilizar para discutir o problema da força se encontra no capítulo VI de $O$ príncipe, justamente onde Maquiavel se ocupa dos principados fundados sobre a virtù. E ali não restam dúvidas acerca de seu teor: basicamente, ela consiste no domínio das armas. Ao invés de valorizar sua dimensão intelectual ou cognitiva (como faz em diversas outras ocasiões) Maquiavel concebe a virtù em termos bélicos. Afinal de contas, esse capítulo se encontra na sequência daqueles que examinam as maneiras de se conquistar o Estado, isto é, de deixar a condição de "homem privado" para tornar-se um "príncipe novo". Sendo um passo importante da argumentação chamar a atenção para a necessidade de possuir armas próprias, Maquiavel recorre a um estratagema ardiloso: ele vai colocar em contraste o caso mais acabado de capacidade persuasiva (a profecia) com o poder das armas, com o propósito de enaltecer as últimas. Dizendo de outra forma, o melhor meio de fazer o elogio das armas é mostrar a limitação da persuasão. Por mais habilidoso que seja o governante no que concerne às aparências, seu domínio é inseguro se não dispõe de armas próprias (aliás, esse ponto de vista será ratificado no capítulo seguinte com o exemplo de César Bórgia). Estas significam autonomia, ao passo que o príncipe que necessita "pedir”, mesmo que seu poder esteja fundado na religião, estará necessariamente na dependência de outrem; logo, está descoberto e sua fragilidade se revela no instante em que seu poder de persuasão se enfraquece. Toda a questão é resumida por Maquiavel da seguinte forma:

É necessário, portanto, querendo discorrer bem sobre este aspecto [sobre os perigos que ameaçam um príncipe novo], examinar se estes inovadores subsistem por si mesmos ou se dependem de outros, isto é, se para levar a diante sua obra precisam pedir ou podem verdadeiramente usar a força. No primeiro caso, saem-se sempre mal e não levam a cabo coisa alguma; mas quando dependem de si mesmos e podem usar a força, então raras vezes correm perigo. Daqui nasce que todos os profetas armados tenham vencido e os desarmados se tenham arruinado. (MACHIAVELLI, 1993, p. 265; MAQUIAVEL, 2008, p. 135-6). 
O poder dos profetas, alicerçado sobre a crença que despertam nos súditos, revela sua fraqueza ao esbarrar na instabilidade do domínio das opiniões. A natureza do povo varia, diz Maquiavel, e "é fácil persuadir de uma coisa, mas é difícil mantê-lo firme nesta persuasão" (MACHIAVELLI, 1993, p. 265; MAQUIAVEL, 2008, p. 136). Por esse motivo, a única via para conferir solidez ao estado é fazer com que o povo, quando não mais crer, "creia pela força” (MACHIAVELLI, 1993, p. 265; MAQUIAVEL, 2008, p. 136). Os “inovadores" que fizeram crer pela força, como Moisés, Teseu, Ciro e Rômulo obtiveram êxito, ao passo que Savonarola, profeta de seu tempo, conheceu a ruína, terminando seus dias na fogueira.

Essa passagem é, no mínimo, surpreendente, e mesmo desconcertante quando cotejada com o que será dito no capítulo XVIII. Entretanto, quando a examinamos com mais atenção, ela se mostra iluminadora. A expressão "fazer crer pela força” destaca, por um lado, o papel fundamental das armas; por outro lado, se não for tomada como uma ironia (e não é assim que a entendemos), ela enreda as armas no mesmo jogo simbólico em que a opinião se constitui. No final das contas, não se trata de substituir o regime discursivo pelo regime da força, mas de fazê-los coincidirem precisamente onde se forma a opinião. Em outras palavras, a força por si só é incapaz de operar no campo político; ela deve distender-se na direção do discurso. Sem que esse passo seja dado, a força não será jamais suficiente para assegurar a obediência, isto é, o assentimento. Portanto, aquele que comanda as armas deverá, em alguma medida, aferir seu significado político. De que vale um exército se o príncipe não consegue apreender o sentido político de suas ações? Este é, sem sombra de dúvida, o autêntico sentido da reprovação que Maquiavel endereçou pessoalmente ao Cardeal de Rouen quando de uma de suas missões na França: “dizendo-me o cardeal de Rouen que os italianos não entendiam da guerra, lhe respondi que os franceses não entendiam do Estado". (MACHIAVELLI, 1993, p. 261; MAQUIAVEL, 2008, p. 125). Essa passagem, do capítulo III de O príncipe, concentra as críticas mais mordazes dirigidas a um governante (Luís XII) em todo o livro. Maquiavel sintetiza os dados de sua experiência diplomática fazendo um apanhado dos erros que levaram o rei da França à sua derrocada na Itália ${ }^{11}$. Munido de um poderoso exército, o rei, assim como seu cardeal, pouco entendia da arte política. Em certa medida, sua figura é o negativo

\footnotetext{
${ }^{11}$ Ver Bignotto (2015, p. 98-9).
} 
de Savonarola, o profeta desarmado: Luís XII é o rei armado que não pode transformar sua força bélica em poder político. Ele "usa" os modos do leão, mas não os da raposa ${ }^{12}$.

Mas voltemos a Savonarola, cuja impressionante retórica ${ }^{13}$ não foi o bastante para conservar seu poder. Maquiavel atribui seu fracasso à "variação" da disposição do povo. Ao invés de enxergar aí uma explicação antropológica, mais vale ater-se ao sentido propriamente político dessa observação. A "natureza" do povo varia na medida em que os fundamentos de seu assentimento são destruídos pelas circunstâncias. O que condena Savonarola à ruína é a simples evidência de que seu poder não tem mais base real. Seus inimigos na cidade são poderosos, o papa o excomunga e ele não dispõe de armas próprias. Nessa situação de extrema fragilidade, nem mesmo o apelo à religião é suficientemente forte para evitar sua queda. A retórica encontra, então, seu limite: ela é correlata a uma significação da realidade política, mas ela não a cria. E aqui o problema da força pode ser lido na chave do realismo de Maquiavel, mas com a precaução de entender esse termo em um sentido preciso: não se trata de uma mera descrição da realidade. Antes, o realismo consiste no reconhecimento de que a política não está sob o completo controle de nenhum de seus agentes. Ela comporta, portanto, uma dimensão que poderíamos chamar de fática. A célebre noção de verdade efetiva, apresentada por Maquiavel no capítulo XV de O príncipe (MACHIAVELLI, 1993, p. 289; MAQUIAVEL, 2008, p. 185), expressa essa dimensão da política, irredutível à vontade e à “imaginação", a qual não pode ser desconsiderada a não ser correndo o risco do fracasso.

Estamos diante de um círculo: em uma direção, o discurso (a retórica, o nível simbólico) aponta sua limitação, deixa entrever seu outro que é a dimensão da força; em outra

\footnotetext{
${ }^{12}$ A exigência de inscrever a força em uma dimensão simbólica é válida em todas as suas variedades. Convém notar que a força não se reduz às armas, embora estas ocupem lugar privilegiado na reflexão maquiaveliana. Mas ela também está presente nas conjuras e nas ações espetaculares, nos feitos extraordinários realizados nas circunstâncias adversas. Por exemplo, as atrocidades de César Bórgia em Cesena, com a execução de Remirro de Orco narrada no capítulo VII de O príncipe. O machado sujo de sangue e o corpo partido ao meio expostos em plena praça pública criam um impacto simbólico incomparável, a ponto de deixar o povo sem palavras: "satisfeito e estupefato", diz Maquiavel. (MACHIAVELLI, 1993, p. 267; MAQUIAVEL, 2008, p. 143). A estupefação é silenciosa, mas a ausência de discurso é preenchida plenamente pelo sentido do ato visto na praça; neste caso, a visão, acompanhada pelo sentimento de satisfação (e também de medo), satura o campo do simbólico, produzindo um significado no interior de cada espectador: o poder de Bórgia excede, em sua violência, o poder brutal de Remirro. E graças a esse gesto teatral, graças a essa retórica muda, ele pôde assegurar-se de seu domínio. O espetáculo da execução de Remirro é um caso limite. Quando a força resvala na violência, está dada a possibilidade de ruptura da rede de significados. Ao invés de produzir o assentimento, o horror do espetáculo poderia ter gerado o ódio. Apenas não o fez porque Remirro era já uma figura odiada. E Maquiavel estava plenamente consciente da periculosidade do jogo de César Bórgia e, por isso mesmo, não nos parece que a admiração que demonstra por ele em certos momentos deva ser tomada em seu valor de face.

${ }^{13}$ Ao jovem Maquiavel, contudo, a retórica do frade já mostrava suas limitações. Na famosa carta a Ricciardo Becchi, de março de 1498, Maquiavel, em tom abertamente irônico, não deixa de alfinetar o frade, denunciando a "mentira" de suas pregações e sua malfadada tentativa de conduzir os florentinos. (MACHIAVELLI, 1993, p. 1010-1012).
} 
direção, o domínio da força requer a abertura para a dimensão simbólica: força sem discurso não enseja poder político. E mais uma vez evocamos a noção de "verdade efetiva" (verità effettuale), cujos termos indicam precisamente os dois aspectos do poder, isto é, a força e o discurso. Com a "verdade" adentramos o campo do sentido, ao passo que a "efetividade" nos mantém na esfera da realidade, do fático, esfera própria da força. Essas relações entre força e discurso podem ser apreendidas - e com grande proveito - quando examinamos a questão da guerra em Maquiavel.

\title{
3 A RETÓRICA DO CAPITÃo
}

No final do livro IV de A arte da guerra, Maquiavel coloca na boca de Fabrizio Colonna as seguintes palavras:

\begin{abstract}
Persuadir ou dissuadir poucas pessoas é muito fácil porque, se as palavras não bastarem, sempre será possível usar a autoridade e a força. Mas a dificuldade é demover uma multidão de uma opinião errada que seja contrária ao bem comum a uma opinião sua. E aí só se podem usar palavras, e é preciso que sejam ouvidas por todos se quisermos que todos sejam persuadidos. Por isso, os excelentes capitães eram oradores porque sem saber falar a todo o exército com dificuldade poderiam realizar boas coisas, o que foi inteiramente deixado de lado em nosso tempo. Leiais a vida de Alexandre Magno e vereis quantas vezes lhe foi preciso discursar a falar publicamente [...] porque serão infinitas as possibilidades de ruína do exército se o capitão não souber falar-lhe ou não tiver esse hábito, porque sua fala dissipa o temor, inflama os ânimos, aumenta a obstinação, revela as fraudes, promete prêmios, mostra os perigos e as vias para escapar-lhes, repreende, roga, ameaça, enche de esperança, louva, vitupera e faz todas aquelas coisas por meio das quais as paixões humanas se extinguem ou se acendem. Por isso, o príncipe ou a república que quiser criar uma nova milícia e lhe conferir boa reputação, deve acostumar seus soldados a ouvir falar o capitão, e o capitão a saber falar àqueles. (MACHIAVELLI, 1993, p. 354; MAQUIAVEL, 2006, p. 135-136).
\end{abstract}

$\mathrm{Na}$ fusão da figura do orador com o capitão de exército vemos o encontro da retórica com a força, sobre o pano de fundo das relações entre política e arte da guerra. Com efeito, como já foi exaustivamente demonstrado pelos comentadores ${ }^{14}$, por diversas vias se comunicam os afazeres políticos e militares. Sem querer retomar essa discussão, interessa a nossos propósitos compreender, a partir dessa passagem, como novamente se articula, nesse texto que trata da arte da guerra, o problema de que tratamos.

\footnotetext{
${ }^{14}$ A lista dos comentadores que exploraram o tema da guerra e da política em Maquiavel é considerável. Um estudo recente (e de ótima qualidade) a respeito é o trabalho de Andrea Guidi (2009).
} 
Aparentemente, esse texto contraria o que Maquiavel havia afirmada no capítulo VI de $O$ príncipe a respeito do profeta desarmado. Mas essa impressão se desfaz quando levamos em conta que ele aborda, por um ângulo diferente, a mesma questão. Maquiavel segue, na verdade, o caminho inverso: se em $O$ príncipe partia do discurso para chegar às armas, agora parte das armas para chegar ao discurso. Além disso, em $O$ príncipe, o problema era vista sob a ótica do homem de poder, e agora sob a ótica do homem da força. Podemos identificar uma simetria: no primeiro caso o agente que pertence por definição ao domínio do discurso sinaliza a existência do outro lugar, o das armas; no segundo caso, produz-se o inverso, quer dizer, o agente da força indica o lugar do discurso.

Contudo, estaríamos enganados se detivéssemos nossa análise nesse ponto. O que a passagem citada acima permite enxergar é a complementariedade entre discurso/retórica e força. Mas como acreditamos ter mostrado, é preciso entender essa complementariedade em seus devidos termos: força e discurso não são domínios radicalmente heterogêneos. Se ambos cumprem uma função na política é porque a passagem entre um e outro é uma exigência da realidade política, o que nos leva a mais uma vez afirmar que a retórica é ela mesma uma forma de ação, e a ação (mesmo aquela que acontece no campo de batalha) contém uma dimensão simbólica.

Por esse motivo, o capitão, que deve ser ao mesmo tempo orador - como preconiza Fabrizio Colonna - compreende claramente que o uso das palavras integra um conjunto mais vasto de estratégias persuasivas. Não causa surpresa a recomendação, presente também no livro IV de A arte da guerra, de que o comandante de exército seja, assim como o homem político, capaz de simular e dissimular: "Se durante a peleja ocorre algum incidente capaz de abalar os teus soldados, é de grande prudência saber dissimular o ocorrido e revertê-lo para o teu bem, como fizeram Túlio Hostílio e Lúcio Sila" (MACHIAVELLI, 1993, p. 350; MAQUIAVEL, 2006, p. 126). Por meio da fraude (ou do inganno, como costumava dizer Maquiavel) é possível persuadir os soldados a lançarem-se contra o inimigo no campo de batalha em situações pouco favoráveis. O texto de Maquiavel é probo na apresentação dos diversos estratagemas para a consecução desse fim, boa parte deles consistindo na manipulação de signos religiosos (a exemplo do que faziam os romanos ${ }^{15}$ ). Mas o que significa a inscrição de arte da guerra no campo da fraude, da simulação e da dissimulação a não ser sua pertença à política, o fato de estruturalmente haver uma comunicação entre

\footnotetext{
${ }^{15}$ A respeito ver o artigo de Benedetto Fontana (1999).
} 
ambas? Que essa comunicação é indiscutível o provam as inúmeras passagens desse mesmo livro IV em que o capitão se transforma na raposa, ou melhor, "utiliza" as duas naturezas: a do leão, que lhe é congênere, e a da raposa, tipicamente astuta.

Interessante sublinhar o problema da astúcia. Em um artigo recente, J. F. Holeindre faz a seguinte observação a esse respeito:

O florentino faz o elogio da astúcia na guerra, precisamente pelas duas razões que explicam em sua obra esse laço tão forte entre arte da guerra e arte política: de início, a astúcia como procedimento tático, fundado sobre o segredo, a enganação e a surpresa, permite vencer certas guerras, notadamente quando as relações de forças estão desequilibradas, e, então, assegurar a liberdade política da cidade. Em seguida, a astúcia como forma de inteligência, como arte da dissimulação e da simulação, é uma componente essencial do poder que o governante exerce na guerra, na diplomacia e, enfim, na ordem interna. (HOLEINDRE, 2014, p. 154).

Como já havíamos assinalado no comentário do capítulo XVIII, é graças à astúcia que se torna possível operar tanto no registro da força quanto naquele do discurso e ela, portanto, unifica as duas naturezas do centauro ${ }^{16}$.

\section{CONSIDERAÇÕES FINAIS}

Para terminar, gostaríamos de reter a figura do centauro. Ela parece encarnar magnificamente o entrelaçamento entre retórica e força, entre persuasão e coerção. Nesse sentido, o centauro é uma imagem privilegiada porque representa a concepção maquiaveliana do poder. Se a ação não pode dispensar o discurso, se ela opera sempre em uma rede de significados, se o poder do príncipe não se separa da representação que os outros dele têm (LEFORT, 1972, p. 404), então o poder integra uma dimensão retórica e persuasiva; por outro

\footnotetext{
${ }^{16} \mathrm{Na}$ impossibilidade de detalhar aqui em que consiste mais propriamente a astúcia, vamos nos servir de uma passagem de Claude Lefort que reforça nosso ponto de vista: "A astúcia, o autor [Maquiavel] a apresenta de início como um atributo da besta no homem, como a paixão cujo símbolo é a raposa, da mesma forma que o leão o é da força. Assim ela é a arte de escapar das armadilhas preparadas pelo adversário. Já reconhecemos, nesse caráter, o valor de um desdobramento que permite tomar o ponto de vista de outrem, conhecer suas intenções e calcular os efeitos de sua conduta própria. Mas Maquiavel evoca na mesma passagem um outro gênero de duplicidade: aquela do príncipe que se faz ao mesmo tempo leão e raposa e, em primeiro lugar, homem e besta, que se coloca sob o signo da lei e sob o signo da força. Nesse deslocamento do sentido da duplicidade se esboça a teoria da astúcia. Todo homem é duplo, simulador e dissimulador, agindo a exemplo da raposa, sob o império ainda da paixão; mas eleva a um outro nível esta duplicidade, ele é 'gran simulatore e dissimulatore' entendemos que ele sabe disfarçar a força em lei e governar pela força da lei, dar à besta figura humana e reprimir também a besta no homem. Em um extremo, a astúcia o enraíza na animalidade e, de fato, ele é movido pela mais viva paixão, aquela do poder; mas, no outro extremo, ela a transcende, pois ele não pode vencer a astúcia dos outros senão as compreendendo, acolhendo suas mentiras, e no momento mesmo em que ele exerce sua força, concordando com eles e os conciliando na dissimulação.” (LEFORT, 1972, p. 411).
} 
lado, se ele não consiste na mera suposição de poder (como, aliás, vai acreditar Hobbes), então ele tem de acolher também a possibilidade do uso da força. Não que a força tenha de ser aplicada de fato, mas não existe poder sem que esteja reconhecida sua presença no horizonte da ação.

O poder, como o centauro, é híbrido, como híbrida é a condição humana. E desconhecer sua dupla face, sua dupla natureza, implica ignorar a especificidade da ação política: ela não é arbitrária, não é mero fruto do desejo humano, mas resulta, em parte, do cálculo e da inteligência. Mas estes jamais são suficientes para eliminar o elemento arbitrário, a imprevisibilidade das paixões, a flutuação das opiniões e a imponderabilidade da liberdade. O centauro é o personagem que não nega nenhuma dessas componentes da realidade, não as rejeita em nome da pureza, não nutre os sonhos de um mundo acabado e harmônico. De certa forma, acolhe as dissonâncias e vive no elemento do conflito.

É bem conhecida a centralidade que Maquiavel concedeu ao tema do conflito em sua obra, e não precisamos aqui recuperar os termos em que ele o fez. Apenas lembramos que, estendido à toda comunidade política ${ }^{17}$, o conflito está na origem do poder político, o que, mais uma vez, atesta sua natureza misturada, impura, histórica. O poder não nasce da força nem da persuasão: ele surge dos confrontos entre os diferentes desejos e, por isso, não pode dispensar a persuasão e a força. Sem uma ou outra, não é possível a constituição de uma comunidade política. E se isso é verdadeiro, o poder não resolve o conflito, mas no espaço aberto por ele nos protege da violência muda e assegura a efetividade da palavra.

\section{REFERÊNCIAS}

ADVERSE, H. Maquiavel: Política e retórica. Belo Horizonte: Editora UFMG, 2009.

AMES, J. L. Verdade efetiva e ação política em O Príncipe de Maquiavel. In: ADVERSE, H. (Org.). Reflexões sobre Maquiavel. 500 anos de O Príncipe. São Paulo: Loyola, 2015.

ARISTOTE. Rhétorique. Tradução de M. Dufour e A. Wartelle. Paris: Gallimard, 1991.

AURÉLIO, Diogo Pires. O mais natural dos regimes: Espinosa e a democracia. Lisboa: Círculo de Leitores, 2012.

BIGNOTTO, N. O aprendizado da força. In: ADVERSE, H. (Org.). Reflexões sobre Maquiavel. 500 anos de O Príncipe. São Paulo: Loyola, 2015.

\footnotetext{
17 "Porque em todas as cidades se encontram estes dois humores distintos [dominar e não ser dominado]", afirma ele no capítulo IX de $O$ príncipe (MACHIAVELLI, 1993, p. 271; MAQUIAVEL, 2008, p. 155, grifo nosso).
} 
FONTANA, B. Love of Country and Love of God: The Politicas Uses of Religion in Machiavelli. Journal of the History of Ideas, v. 60, n. 4, out. 1999.

GUIDI, A. Un segretario militante. Politica, diplomazia e armi nel cancelliere Machiavelli. Bolonha: Il Mulino, 2009.

HOLEINDRE, J. V. Guerre et Politique selon Machiavel: La Centralité de la Ruse. In: Ligio, G. de (Org.). Le Problème Machiavel. Paris: Instituto Italiano di Cultura, 2014.

LEFORT, C. Le travail de l'œuvre Machiavel. Paris: Gallimard, 1972.

MACHIAVELLI, N. Tutte le opere. Florença: Sansoni, 1993.

MAQUIAVEL, N. A arte da guerra. Tradução de MF. São Paulo: Martins Fontes, 2006.

MAQUIAVEL, N. O príncipe. Tradução de Diogo P. Aurélio. Lisboa: Círculo de Leitores, 2008 .

MÉNISSIER, T. Machiavel ou la politique du centaure. Paris: Hermann, 2010.

RICCEUR, P. Lectures 1. Autour du politique. Paris: Gallimard, 1991. 